Caring for the Vulnerable Geriatric Individual in a Disaster Dr. Sharon Mace ${ }^{1}$, Dr. Connie Doyle ${ }^{2}$

1. Cleveland Clinic Lerner College of Medicine at Case Western Reserve University, Cleveland, United States

2. St. Joesph Mercy Hospital, Ann Arbor, USA

Introduction: The elderly have the highest rates of morbidity/ mortality in a disaster and are therefore the most vulnerable. $50 \%$ of deaths in Hurricane Katrina were $\geq 75$ years old. In the California wildfires, most deaths were people in their 70 s and 80s living in areas with unreliable communication services (without cell phone service, etc.), and were uninformed of the disaster or unable and/or unwilling to evacuate. Issues include social isolation and limited technology skills (may not receive messages).

Methods: A review of the literature and after action reports from multiple disasters.

Results: Augmented services are needed for persons with decreased mobility (impaired access to transportation and shelters); impaired senses; dependence on devices/technology, comorbidities requiring medications/equipment/oxygen, special feedings, sanitary/hygiene needs increased susceptibility to environmental extremes (heat, cold), inability to do ADLs (need for caregivers), increased susceptibility and increased morbidity/mortality with infections, illnesses, trauma; exacerbation of underlying conditions/illnesses when in crowded transportation vehicles and shelters. Additional stress may precipitate or exacerbate coping skills especially in those with dementia, delirium, or mental health illnesses.

Discussion: Recommendations include the following:

1. Communications: messages in various forms: closed captioning, TTY deaf phones, use of family, friends, neighbors, officials for notification in addition to mass communication notices, house-to-house notification.

2. Medical: Medical/Special Needs Shelters to provide medical care (dialysis, etc.), cache of common medications (diabetic and $\mathrm{BP}$ medications) and devices (BP monitoring, glucometers), oxygen, wound care supplies, potable and non-potable water, special diets/formulas, feeding tubes, catheter care, diapers and other hygiene supplies.

3. Independence: Health care professionals to assist with medical and psychiatric needs. Caregivers to assist with ADLs.

4. Supervision: Those with dementia, delirium, mental health conditions may need supervision.

5. Transportation: Need for ambulances, wheelchair vans, specially equipped buses/vans in addition to "usual" school buses/vans with access to water, food, and sanitation if traveling long distances.

Prehosp Disaster Med 2019;34(Suppl. 1):s107

doi:10.1017/S1049023X19002231

Challenges in Dealing with Supervised and Institutionalized Populations in a Disaster

Dr. Sharon Mace, Dr. Connie Doyle

Cleveland Clinic, Cleveland, United States

Introduction: Those residing in supervised facilities including nursing homes, mental health facilities, group homes, and penal institutions for health, legal, or security reasons present unique challenges in a disaster.

Methods: A review of the literature and after action reports on supervised and institutionalized populations in disasters.

Results: Recommendations for supervised, institutionalized populations in a disaster include: (1.) preplanned agreements for specialized transportation if needed; (2.) reciprocal agreements between similar facilities (nursing home with another nursing home, prison with other prison, dialysis centers, etc.) for resource sharing; (3.) arrangements for sharing and emergency privileging of personnel in institutions that are not their primary workplace; (4.) just-in-time training for appropriate volunteers; and (5.) accommodations for family members if personnel are to be available during a disaster.

Individuals in some institutions need a personalized disaster plan with pertinent data: next of kin with contact information, medical records, care providers and care plan to accompany a mobilized individual. Long-term care and housing may be needed if the institution is nonfunctional. Dealing with medical and behavioral issues is secondary to the disaster. Chronic issues must be considered as well.

Discussion: Caring for specialized, institutional individuals is complex and difficult. Comprehensive pre-disaster planning can mitigate the effects of the disaster.

Prehosp Disaster Med 2019;34(Suppl. 1):s107

doi:10.1017/S1049023X19002243

\section{Chemical and Radiation Training for Public Health and Nursing Students: An Under-Utilized Disaster Response Demographic}

Dr. Sukbi Atti, Dr. Emily Kiernan, Dr. Mark Layer, Dr. Aynur Sabin, Dr. Shaikhah Alotiabi, Dr. Waleed Als uk aiti, Sydney Shuk, Kayla Lindros, Dr. Tyler Giberson, Dr. Ziad Kazzi Emory University Medical Toxicology Fellowship, Atlanta, United States

Introduction: Public health $(\mathrm{PH})$ and nursing students are an underutilized demographic in disaster response. Knowledge of the disaster response phase may enhance student understanding of preparedness, and provide response capabilities.

Aim: A single four-hour simulation-based training session, with toxicologists as instructors, can effectively improve $\mathrm{PH}$ and nursing student knowledge and skills in chemical and radiation response, despite minimal prior experience.

Methods: A convenience sample was used to test $\mathrm{PH}$ and nursing students in a response training program. An introductory lecture and simulation training reviewed: mass casualty care, triage, personal protective equipment, decontamination, and chemical and radiation exposure toxidromes. An examination was administered pre-training, and then post-training, to evaluate relevant training, knowledge, risk perception, and comfort in response capabilities to chemical and radiation incidents.

Results: Forty-two students attended the course; 39 were included in the study. Seventy-two percent $(n=28)$ of participants had no prior disaster training. Overall, there were significant differences between the pre-test and post-test scores for all students [95\% CI: 5.4 (4.7-6.1); p<0.0001, paired t-test]; maximum score 15/15. Comparing scores of nursing and $\mathrm{PH}$ 
students, despite statistical difference in pre-test scores

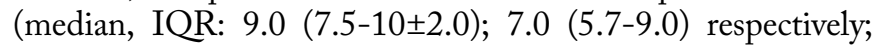
$\mathrm{p}=0.048$, Mann Whitney U-test), there were no statistical differences in post-test scores (median, IQR: 14.0 (13.014.0); 13.0 (12.0-14.0), respectively, Mann Whitney U-test). All students recognized nerve agent toxidrome and performed SALT triage after the training ( $p<0.0001, \mathrm{McNemar}$ test). Subjectively, participant comfort level in responding to a chemical or radiological incident improved ( $p<0.0001, \mathrm{McNemar}$ test). Individual risk perception for chemical or radiological disasters did not improve after training.

Discussion: Improvement of knowledge and comfort was demonstrated, irrespective of previous experience. Simulation-based training of chemical and radiation disaster preparedness, led by medical toxicologists, is an effective means of educating $\mathrm{PH}$ and nursing students, with minimal prior fluency.

Prehosp Disaster Med 2019;34(Suppl. 1):s107-s108

doi:10.1017/S1049023X19002255

\section{Chemical Response Emergency Medical Information System in Chemical Disaster \\ $M r$. Soon-Joo Wang ${ }^{1}$, Mr. Seongyong Yoon ${ }^{2}$ \\ 1 Hallym University, Hwaseong, South Korea \\ 2 Sooncheonhyang University, Gumi, South Korea}

Introduction: There are many database sets and websites which provide chemical information, but they do not perform an adequate role for emergency medical support in a chemical disaster.

Aim: To make the basis of a chemical emergency medical information system.

Methods: We reviewed the database sets, mobile applications and websites in the world which provide chemical database and emergency medical response information from a chemical accident or disaster site to hospitals. Also, we examined chemical accident cases which developed during disasters. A chemical database set for emergency medical response was proposed and the algorithm for elicitation of chemicals suitable for emergency medical response and information providing. We performed a survey about chemical emergency medical information system to related personnel.

Results: By four steps of elicitation of chemicals, the number of chemicals more than 100,000 was decreased to less than 1,000. The standard of steps includes accident preparedness, toxicity and circulating amount and expert consultation. Algorithm for elicitation of chemicals was made and $82 \%$ of related personnel supported the chemical emergency response algorithm. The emergency medical real-time consultation system for chemical disaster was placed under control of the call center.

Discussion: When mass exposure by toxic chemicals occurs, the chemical emergency medical information system will be helpful for acute identification of chemicals, protection of related personnel and emergency medical response. Also, it can be possible to guide citizens immediately in case of a chemical disaster.

Prehosp Disaster Med 2019;34(Suppl. 1):s108

doi:10.1017/S1049023X19002267
Collaboration between a Hospital and the Surrounding Communities in an Emergency and Disaster Dr. Ahmad Alim ${ }^{1,7}$, Budi Santosa ${ }^{1}$, Budi Setiawan ${ }^{1}$, Dr. Rabmawati Husein ${ }^{1}$, Arif Nurkholis ${ }^{1}$,

Dr. Zubdiyah Nihayati ${ }^{1}$, Dr. Corona Rintawan ${ }^{1}$, Dr. Iin Inayah ${ }^{1}, A l$ Afik ${ }^{1}$, Dr. Tri Arliono ${ }^{1}$, Ali Haedar ${ }^{2}$, Dr. Syabirul Alim ${ }^{3}$, Danang Samsu', Eny Supartiny, Husnan Nurjuman ${ }^{6}$

1. Muhammadiyah Disaster Management Center, Yogyakarta, Indonesia

2. Ahmad Dahlan University, Yogyakarta, Indonesia

3. Brawijaya University, Malang, Indonesia

4. Gadjah Mada University, Yogyakarta, Indonesia

5. Provincial Disaster Management Authority, Yogyakarta, Indonesia

6. National Disaster Management Authority, Jakarta, Indonesia

7. Muhammadiyah Health Board, Jakarta, Indonesia

Introduction: Muhammadiyah, the Indonesia non-governmental organization (NGO), has more than 300 hospitals. It is one of the forerunners of the Safe Hospital Initiative in Indonesia beginning in 2008. Muhammadiyah realized that hospital strengthening must be done in collaboration with community strengthening. From 2016 to 2018, Muhammadiyah ran a program named Hospital Preparedness and Community Readiness for Emergency and Disaster (HPCRED) that was carried out through strengthening two hospitals and their surrounding communities in Palangka Raya, Central Kalimantan, and Bima, West Nusa Tenggara (NTB). This program was funded by the Australian Government and is in line with the Safe Hospital Comprehensive Framework of the World Health Organization (WHO).

Aim: To strengthen hospitals and the surrounding communities to prepare for emergencies and disasters.

Methods: HPCRED completed 92 activities in two areas consisting of the following: 10 training, 26 workshops, 12 exercises, four monitoring and evaluation meetings, and seven technical sessions/seminars. The exercises consisted of tabletop exercises, skill drills, command post exercise, and full-scale exercise.

Results: There were positive changes in the hospitals and communities particularly on disaster management, policy, procedures, staff and community skills, knowledge, and behavior. The integration and collaboration between the hospital surrounding communities were established and can be examined by documents, agreements, and activities done together between the hospital and community during and after the program.

Discussion: Before the program, hospitals were not ready to face disasters. PKU Bima Hospital collapsed during a flash flood in December 2016. The community, to save housing from water, hollowed the hospital wall out causing water entrance into the hospital. It meant there were no communication and coordination between the hospital and its community. HPCRED not only made them communicate and coordinate but also collaborate and cooperate to reduce risks and response disasters such as responding Lombok Earthquake in July 2018.

Prehosp Disaster Med 2019;34(Suppl. 1):s108

doi:10.1017/S1049023X19002279 